\title{
Análise do discurso feminino sobre casamento e maternidade na perspectiva simbólica junguiana
}

\author{
Analysis of feminine discourse about marriage and motherhood in symbolic jungian perspective
}

Alana Cristine Durelli Brunini Malerbo ${ }^{[a]}$, Mariana Araújo Noce ${ }^{[b]}$

\footnotetext{
${ }^{[a]}$ Graduada em Psicologia, Universidade de Ribeirão Preto (Unaerp), Ribeirão Preto, SP - Brasil, e-mail: alanabrunini@gmail.com

${ }^{[b]}$ Doutora em Psicologia, Universidade de São Paulo (USP) Ribeirão Preto, SP - Brasil, e-mail: mnoce@unaerp.br
}

Recebido: 11/08/2011 Received: 08/11/2011

Aprovado: 18/10/2011 Approved: 10/18/2011

\section{Resumo}

Este estudo aborda histórias de vidas de mulheres a partir da perspectiva simbólica junguiana. Participaram da pesquisa duas mulheres, ambas com 54 anos de idade, casadas e com dois filhos, as quais foram submetidas à aplicação da técnica "Linha da Vida", em que foi solicitado que marcassem, em uma folha, momentos significativos de suas vidas e, posteriormente, os explicassem com base nos fatos ocorridos e nos sentimentos emergentes. A análise ocorreu a partir do levantamento de questões relacionadas ao casamento e maternidade e, assim, identificar e relacionar essas vivências com os elementos arquetípicos e do inconsciente coletivo. Observou-se que ambas apontaram como primeiro ponto significativo de suas vidas o casamento, ambas incluíram, ainda, o nascimento de cada um dos dois filhos e destacaram a morte de seus respectivos pais. Tais passagens estão entre as que a literatura aponta como significativas na vida das mulheres, carregando a força dos arquétipos e sendo representadas em mitos e contos de fadas. Na perspectiva junguiana, os contos de fada constituíram para a expressão do pensamento mítico, por desempenharem uma função psíquica importante relacionada ao processo de individuação. Esses arquétipos, ao serem trazidos à consciência e vivenciados, permitem à psique cumprir as etapas de integração progressiva de conteúdos e aspectos inconscientes. Conclui-se, então, sobre a importância do estudo de tais assuntos para compreensão do feminino e da necessidade de investigação da presença e função dos contos de fadas na vida dos indivíduos.

Palavras-chave: Vivências femininas. Contos de fadas. Psicologia Analítica.

\begin{abstract}
This study deals with stories of women's lives from the perspective of jungian symbolics. Two women, both 54 years old, married with two children participated this study who were submitted to the application of the "Life Line" technique, in which they were asked to mark significant moments of their lives on a sheet, and then explain the basis for the fact and feelings emerging. The analysis was based on a survey of issues related to marriage and motherhood, and thereby identify and relate these experiences to the archetypal elements and the collective unconscious. It was noted that both appointed marriage as the first significant point in their lives, both included, the birth of each of their two children and highlighted the death of their parents. These passages are among those literature indicates as significant in the lives of women, carrying the force of archetypes and are represented in myths and fairy tales. In jungian perspective, fairy tales were, for
\end{abstract}


the expression of mythical thought, because they play an important psychic function related to the process of individuation. These archetypes, when brought to consciousness and experienced enabled the psyche to attend milestones of progressive integration of content and unconscious aspects. It was concluded on the importance of such study matters to understand the feminine, and the need to investigate the presence and function of fairy tales in the lives of individuals.

Keywords: Women's experiences. Fairy tales. Analytical Psychology.

\section{Introdução}

0 presente estudo teve como objetivo observar como os contos de fadas estão presentes na vida da mulher em seus relacionamentos amorosos, em suas concepções de mãe/mulher e nas idealizações construídas no decorrer de sua vida. E, a partir disso, estabelecer possíveis relações dos relatos da vida dessas mulheres, com os arquétipos e os temas presentes nos contos de fadas, de maneira a identificar quais contos de fadas e imagens arquetípicas femininas possuem em relação ou influência direta ou indireta no decorrer da vida dessas mulheres.

A origem dos contos de fadas, segundo Von Franz (1990), parece residir em uma potencialidade humana arquetípica (aliás, não somente os contos de fada, como todas as fantasias). Os contos de fadas existem há milênios. Em diversas culturas, em todos os continentes, existem histórias com estruturas e narrativas semelhantes aos contos que existem hoje. Esses contos costumam encantar pessoas de qualquer faixa etária, pois reproduzem, em seu enredo, a passagem por todos os estágios da vida humana.

Como afirma Giglio (1999), os contos de fada constituíram, por meio dos séculos, instrumentos para a expressão do pensamento mítico, perpetuando-se no tempo por desempenharem uma função psíquica importante relacionada ao processo de individuação. A partir deles, toma-se consciência e vivenciam-se arquétipos do inconsciente coletivo. Estes arquétipos, por sua vez, ao serem trazidos à consciência e dramaticamente vivenciados permitem à Psique cumprir as etapas de integração progressiva do desenvolvimento da persona, conscientização da sombra, confrontação com a anima/ animus e outros arquétipos, e finalmente atingir um estado em que a comunicação Ego-Self seja fluente e criativa (Thompson, 1969).
É importante ressaltar que "Um arquétipo é uma forma de pensamento ou de comportamento, um símbolo das experiências humanas básicas, que são as mesmas para qualquer indivíduo, em qualquer época e qualquer lugar" (Mendes, 2000). Para Jung (1984), o mapa da alma é formado por várias camadas, sendo a dos arquétipos a mais profunda. Nessa camada, não existe nada de individual ou único nos humanos e, sim, o inconsciente coletivo, comum a todos os humanos, independente de sua raça, cultura ou classe social. Este traz o caráter de universalidade das suas ideias. Porém, o ser humano é também singular, e a construção dessa singularidade é o produto de uma luta pessoal pelo desenvolvimento e aquisição da consciência.

Antes de fazer a relação dos contos de fadas com o feminino, é necessário caracterizar o que é a feminilidade que se relaciona ao caráter, ao modo de ser e de pensar próprios da mulher. As qualidades psíquicas tipicamente femininas são, no entanto, adquiridas ao longo da vivência, visto que ao nascer, segundo Jung, essas potencialidades estão presentes em todas as espécies (Whitmont, 1969); logo, seguir padrões femininos não é algo biologicamente imposto. Os desejos de individuação e de identidade não são privilégios femininos, mas, sem dúvida, caracterizam o feminino.

Segundo Von Franz (1995), o objetivo dos contos é a individuação, a realização da totalidade psíqui$\mathrm{ca}$, a descoberta da verdade interna e única que se define na união do princípio masculino e feminino que, nos contos, se dá com a união de rei e rainha, príncipe e princesa.

São muitas as passagens que as mulheres vivenciam ao decorrer da vida: nascimento, menstruação, casamento, gravidez, amamentação, menopausa e morte.

Dentro do casamento, Jung denominou de Conjuctio a união dos arquétipos da anima e do animus no vínculo conjugal. Assim, o casamento possibilita a individuação, 
na medida em que o inconsciente do outro expressa o próprio inconsciente do indivíduo. É preciso ser consciente de si para poder distinguir-se do outro e, assim, relacionar-se com ele. Quanto maior for a extensão da inconsciência, mais a escolha do parceiro é influenciada pelas imagens arquetípicas internas do animus e da anima (Vargas, 1989).

Para Sanford (1987), anima significa o componente feminino numa personalidade de homem e animus designa o componente masculino numa personalidade de mulher. São os parceiros invisíveis presentes em todos os relacionamentos humanos e em toda busca da plenitude individual por parte das pessoas. Como são projetados, geralmente não são fáceis de serem reconhecidos nos indivíduos, pois parecem estar fora das percepções.

Thompson (1969) relata que existe um lado masculino e um lado feminino presente em cada indivíduo. Se o masculino é dominante, o feminino é recalcado. 0 indivíduo necessita desenvolver ambos os aspectos. 0 lado feminino recalcado do homem é denominado anima, o lado masculino da mulher é o seu animus.

Varjão (2009) relata que a imagem da anima é projetada primeiramente na mãe, ou na mulher que fizer seu papel, e depois, essa imagem poderá ser transferida para a professora, a irmã, a namorada ou a esposa. Se, nessa projeção, há um exagero, existe uma desproporção entre a mulher amada e a fantasia criada pela anima podendo ocorrer de o homem querer repetir com a companheira a relação que teve ou esperava da mãe. Essa projeção recebe o nome de complexo materno.

Segundo Estés (1994), para algumas mulheres a prova da natureza ocorre durante a gravidez, durante a amamentação, durante o milagre das mudanças que surgem à medida que se educa um filho, durante os cuidados que dispensamos a um relacionamento amoroso. A maternidade traz a experiência de uma possibilidade no processo de individuação do feminino, trazendo a passagem de filha para mãe. A gravidez, assim como o parto, é um acontecimento da esfera biopsicossocial e o inconsciente responde a ambos com informações arquetípicas, constelando principalmente o arquétipo materno.

A maternidade traz mudanças intensas na vida da mulher, principalmente no que concerne à sua identidade, pois o nascimento de um filho implica no nascimento de uma "mãe" para esse filho. "A mulher passa por uma mudança simbólica radical em sua consciência de si mesma ao tornar-se mãe" (Gallbach, 1995, p. 43).

"Quando ocorre o nascimento e com ele se conclui a transformação da mulher em mãe, põe-se em atividade uma nova constelação arquetípica, a qual remodela a vida da mulher até suas camadas mais profundas" (Neumann, 1995, p. 40). A modalidade arquetípica a qual se refere Neumann é o arquétipo materno.

Ao tornar-se responsável pelo bebê, ao cuidar dele e alimentá-lo, a mulher encontra a possibilidade de cuidar-se e nutrir-se, tornando-se responsável pela vida em si e pela sua própria vida. Para tanto, faz-se necessário o sacrifício da filha, nutrida e protegida, para a iniciação da mãe que nutre e protege, vivenciando simbolicamente uma espécie de morte e renascimento, "o nascimento de um primeiro filho representa 'morrer' como jovem e 'renascer' como mãe" (Gallbach, 1995, p. 82).

\section{Métodos}

Antes do início da coleta, este trabalho passou pela aprovação do Comitê de Ética em pesquisa da Universidade de Ribeirão Preto (Unaerp). 0 projeto foi realizado segundo as normas éticas, respeitando-se o anonimato, o sigilo e os direitos dos sujeitos que participaram da pesquisa de forma voluntária, não recebendo remuneração para a participação.

A metodologia utilizada foi a de um estudo exploratório, que se constitui como um dos possíveis métodos de pesquisa qualitativa.

Para se atingir o objetivo de forma organizada e estruturada, o trabalho foi desenvolvido, primeiramente, na realização de uma pesquisa bibliográfica sobre o tema escolhido, pontuando os principais conceitos de Jung e a psicologia analítica.

Os sujeitos foram selecionados de acordo com o objetivo do trabalho, constituindo uma amostra de conveniência. Foi solicitada a participação voluntária, de duas mulheres, de 54 anos, casadas há mais de 25 anos, tendo dois filhos. As escolhas dessas características ocorreram com base nos objetivos propostos, e porque tais mulheres apresentam casamentos duradouros e também convivência com os filhos, sendo possível investigar vivências, reflexões e principais momentos marcantes para essas mulheres a fim de estabelecer relações com os contos de fadas e os arquétipos. 
Os dados foram coletados nos locais de preferência de cada entrevistada, em geral em suas próprias residências. Buscou-se um lugar calmo, que permitiu a liberdade de expressão e a privacidade, não ocorrendo interrupções. Os dias e horários foram agendados de acordo com a disponibilidade das participantes.

As entrevistas foram gravadas (conforme autorização dos sujeitos) para manter a fidelidade e a fidedignidade das respostas.

A coleta de dados ocorreu em dois encontros com duração aproximada de cinquenta minutos cada.

No primeiro encontro, foram explicados os objetivos e os métodos da pesquisa, solicitando-se a colaboração voluntária dos sujeitos e entregue o Termo de Consentimento Livre e Esclarecido às participantes, contendo todas as informações necessárias quanto ao objetivo do trabalho. Foi realizado um rapport para favorecer a criação de um vínculo que possibilitasse que as participantes fornecessem as informações necessárias para o cumprimento do projeto e também foram coletadas informações objetivas a respeito da trajetória de vida das participantes.

Ainda o primeiro encontro, foi iniciada a aplicação da técnica "Linha da Vida", que foi utilizada a fim de se obter aprofundamento sobre o universo íntimo das entrevistadas, evocando, assim, fatos considerados marcantes em cada etapa de suas vidas. 0 processo de aplicação também possibilitou a elas aumentarem as informações sobre si e manter uma organização de fatos e acontecimentos. Foi solicitado aos sujeitos que incluíssem na linha o que esperavam realizar nos próximos anos.

Após o primeiro encontro, foi agendado um segundo contato para a continuidade da realização da entrevista. Esse contato durou aproximadamente cinquenta minutos, que teve como objetivo aprofundar os pontos levantados pela "Linha da Vida" e uma investigação detalhada de suas histórias de vida.

\section{Resultados}

Após leitura atenta das entrevistas, baseadas nas questões norteadoras deste estudo, foi possível a compreensão de uma série de vivências das entrevistadas, a partir de relatos de suas histórias de vida, destacando-se assuntos relacionados "ao casamento" e "à maternidade".

Para se comporem os resultados do presente trabalho, primeiramente serão apresentados resumos das informações prestadas pelas participantes durante a aplicação da técnica "Linha da Vida" e, em seguida, destacar suas opiniões sobre casamento e maternidade. É importante destacar que os nomes apresentados a seguir serão nomes fictícios, para manter a identidade das mulheres.

A entrevistada Diva tem 54 anos, é casada e tem dois filhos. Na técnica "Linha da Vida" marcou primeiramente o casamento que ocorreu quando ela tinha 20 anos, em seguida marcou o nascimento dos filhos, que ocorreram quando ela possuía 21 e 29 anos, e, após, marcou o falecimento dos pais. Tal fato ocorreu quando a entrevistada possuía 41 anos, e ainda é um momento marcante em sua vida. Notouse que, quando ela começou a falar sobre esse tema, seus olhos encheram de lágrimas, e ela preferiu encerrar seus comentários.

Na entrevista, é importante destacar que, durante a adolescência, ela teve amigos, mas logo começou a namorar, e este atualmente é seu marido.

Em relação às gestações, Diva relata que a primeira não foi planejada, mas foi desejada; já a segunda gestação foi planejada e desejada. Diva responde que, para ela ser mãe, é algo prazeroso, é toda uma experiência, considerando que, para ser uma boa mãe, é preciso saber educar os filhos com muito amor e paciência.

Quando questionada sobre o que é ser esposa, Diva relata que é uma luta constante, pois a mulher tem que saber se dividir, entre mãe, mulher, trabalhadora e dona de casa. É possível observar quando ela diz: "a vida da gente não é fácil, tudo a gente tem que pensar, refletir, fazer, é tudo difícil... A gente faz, mas tem recompensa, tudo vem, mesmo que não é rápido vem". Para ela para ser uma boa mulher é necessário ser honesta, fiel e estar presente junto ao marido.

A entrevistada Norma tem 54 anos, é casada e tem dois filhos. Na técnica "Linha da Vida", marcou primeiramente o casamento com 29 anos; em seguida, marcou o nascimento da filha, que ocorreu quando a entrevistada possuía 30 anos, depois foi marcada sua mudança para Inglaterra que ocorreu quando ela tinha 34 anos. Lá morou aproximadamente um ano e meio, e o motivo de tal mudança foi acompanhar o marido. Ao retornar para o Brasil, ela pontua que, aos 36 anos, nasceu o segundo filho, e aos 52 anos marcou que ocorreu o falecimento de seu pai. Relata ainda que este foi um fato que a marcou bastante, pois não morava na mesma cidade 
que seus familiares, e a morte de seu pai ocorreu de forma inesperada.

Quando questionada sobre namoro, relata ter tido somente um namorado, que foi com quem ela se casou. Em uma de suas respostas, a entrevistada Norma respondeu que casar é sair da condição de filha e passar à condição de esposa.

Sobre as gestações, disse que foram desejadas, e ela relatou se relacionar bem com os filhos, pois não trabalhava quando os filhos eram pequenos, então teve tempo para aproveitar a infância deles. Relata que ser mãe "é uma experiência e tanto, é cuidar bem deles, tanto na parte de dar carinho e atenção, como também alimentação, educação, e também num é dar tudo, tem que ter um limite". Falou que atualmente os filhos fazem faculdade longe da cidade em que ela reside, e às vezes, a saudade é ruim, mas já está se acostumando. Ela complementa dizendo que, para ela ser mulher, é um dom, pois a mulher pode gerar uma vida dentro de outra.

É relevante notar que, nesta amostra, ambas as mulheres têm 54 anos, são casadas, possuem dois filhos (uma mulher e um homem) e trabalham em uma instituição de ensino, porém com funções diferentes. As duas mulheres namoraram durante sete anos antes de se casarem, sendo que tal casamento foi com o primeiro namorado que tiveram. Em relação às características em comum das participantes, é relevante citar que esta coincidência ocorreu de forma não intencional, tendo sido possível perceber tais pontos em comum após a realização das entrevistas.

0 primeiro ponto a ser destacado em relação à técnica "Linha da Vida" é que ambas as participantes tiveram facilidade em situar os pontos significativos de suas trajetórias de vida.

Comparando-se as duas participantes, é interessante notar que ambas marcaram como primeiro momento significativo seus casamentos, não tendo marcado nenhum outro fato antes dessa data. Também, ambas colocaram o nascimento dos filhos e a morte dos pais.

As duas mulheres tiveram vários amigos durante a adolescência e ambas namoraram apenas uma pessoa, com a qual se casaram. Diva relata: "Eu tinha bastante amigos. Mas namorado eu só tive um meu marido, namorei e casei" e Norma relata que nunca brigou, e casou-se com o primeiro namorado: "... nunca separamos, nunca brigamos, e ele foi meu primeiro namorado".

É possível notar, a partir da entrevista, que ambas as mulheres namoraram sete anos e se casaram com o primeiro namorado. Ambas as entrevistadas relataram que as gestações foram desejadas. Diva casou-se grávida e, como relatou, a primeira gestação não foi esperada, mas foi desejada, e a segunda gestação foi planejada. Norma, por sua vez, relatou que ambas as gestações foram desejadas e planejadas.

Diva relata que, nos primeiros anos de vida de seus filhos, trabalhava e não possuía muito tempo para ficar com eles, porém isso não atrapalhou no crescimento deles, enquanto Norma possuiu mais tempo para os seus filhos.

Quando foi feita a pergunta de como é ser mãe e o que elas consideram ser uma boa mãe, ambas responderam confirmando o que já estava explícito, que ser mãe é dar carinho, proteção e cuidar dos filhos com atenção.

E em relação ao que pensam sobre o que é ser mulher, ambas responderam que é ser mãe, esposa, profissional, respeitar e educar com limites.

\section{Discussão}

Este estudo buscou relacionar experiências e vivências de mulheres sobre casamento e maternidade com os contos de fadas. Após o levantamento dos resultados, foi feita a análise e a discussão dos dados obtidos.

É importante ressaltar que, neste estudo, houve a escolha pela investigação com o gênero feminino e, portanto, os aspectos enfatizados dirão respeito principalmente às vivências arquetípicas femininas.

Assim, um aspecto importante apontado pelas mulheres desta amostra, em relação ao casamento, é que ambas as entrevistadas, como dito anteriormente, casaram-se com o primeiro namorado. Deve-se lembrar que, na escolha do parceiro, o que geralmente ocorre entre os casais, é que estes vão ao encontro do que a pessoa busca na outra, tendo assim, a realização da relação. De acordo a descrição de Di Yorio (1996, p. 20), a escolha de um parceiro geralmente envolve um complexo 'arsenal' de motivações, ligadas a vivências emocionais muito íntimas e profundas. "[...] Misturam-se desejos de várias ordens, e quanto mais inconsciente o indivíduo estiver em relação a esses desejos, maior a possibilidade de tais conteúdos serem 'fisgados' nessa relação".

É interessante notar, no presente estudo que, assim como nos contos de fadas não há relato das personagens namorarem mais de um homem, 
geralmente elas conhecem o príncipe, começam a namorar, casam e vivem felizes para sempre.

Segundo Sharp (1993), Coniunctio é um termo alquímico que define uma operação na qual os opostos de uma massa caótica são separados e depois reunidos em uma forma estável. O Arquétipo da Coniunctio, que refere à união e à separação, está na base da instituição do casamento e geralmente é responsável pela atração original entre duas pessoas no estágio de enamoramento. Além do papel de homem e mulher, os parceiros exercem os papéis sociais de marido/esposa e de pai/mãe, os quais têm como base as vivências parentais de cada um.

É possível notar a presença desse arquétipo na fala da participante Norma, quando perguntado sobre o casamento: "A gente já namorava, e o casamento só foi para oficializar mesmo a união. Este mudou minha vida, por que me fez sair da condição mãe, pai e irmãos, para ir morar com quem eu escolhi".

A esse respeito, Vargas (2004) complementa que é possível dividir a vida em duas grandes fases: a parental - ligada ao mundo dos pais; e a adulta - quando se conquista individualidade, atingindo uma identidade plena e profunda. É possível observar o arquétipo da conjugalidade (da Anima e do Animus), tornando o ego plenamente adulto e se desenvolvendo na relação com o outro que se escolheu para viver, e construindo uma união.

A entrevistada Diva relatou:

Lembrei de uma coisa que eu queria falar... o casamento não é as mil maravilhas, tem briga, tem os cricas né, resmunga de muita coisa, mas eu não ligo não, to nem ai, mas às vezes também enche o saco... enfim não é às mil maravilhas. A gente passa pelos altos e baixos ... mas era só isso que eu queria acrescentar.

Nesse pequeno recorte, é possível fazer uma relação com o que Guggenbuhl-Craig (1980, p. 28) cita sobre o casamento desenvolver-se em duas situações:

A primeira, considerando o casamento como um meio de individuação, ou seja, descobrir a própria alma através do confronto com o outro. Nesse caso, os conceitos de normalidade matrimonial seriam relativos, pois o caminhar de um casal em direção à individuação é singular e não segue um padrão dos costumes e moral vigentes. A segunda, tratando da concepção do casamento de bem-estar, a qual o autor considera falida, uma vez que a convivência diária e rotineira gera inevitáveis confrontos e conflitos.
A partir do recorte da fala de Diva, é possível notar que a rotina gera conflitos e é normal haver discussões no casamento, que ninguém terá uma relação sem brigas. Elas são necessárias para o desenvolvimento do casal, pois geralmente ocorrem quando há divergências e estas favorecem o aparecimento da individuação.

Com a entrada na individuação, dá-se início à retirada e à integração das projeções, ou seja, essa integração acontece quando um conteúdo psíquico mantido inconsciente passa a fazer parte do EU consciente e começa a ser entendido como parte integrante do todo.

Sobre o processo de individuação, é possível notar que ele naturalmente mais inclinado para a mulher, pois a mulher amplia sua consciência por meio da integração de conteúdos inconscientes e estão mais abertas às experiências, e, a vivência do Animus, traz à mulher a capacidade de reflexão, autoconhecimento e gosto pelas coisas do espírito.

Bettelheim (1980) esclarece a afirmação do casamento provocar a ideia de que não haverá mais angústias, nem frustrações, após o encontro do amor. Sob o efeito dos ideais românticos, as pessoas creem que, após o casamento, nada de ruim irá acontecer, que a felicidade será plena, mas isso nem sempre é possível.

O casamento ainda é visto por Vargas (2004) como um organismo vivo e criativo, que irá gerar filhos concretos ou simbólicos em diferentes áreas da personalidade humana: biológica, social, cultural, psicológica, etc. Assim, o vínculo conjugal sadio é aquele que permite o desenvolvimento individual dos parceiros e é caracterizado por uma vivência dialética criativa. Isso não significa um estado de perfeito entendimento entre o casal ou ausência de conflitos, mas a elaboração desses conflitos mesmos de forma dinâmica, transformando-os em aspectos propulsores de crescimento e enriquecendo a relação.

Nota-se que ambas as mulheres não marcaram acontecimento antes do casamento, e Mendes (2000) destaca que, nos contos de fadas, a princesa (ou moça pobre que se torna princesa) representa o caminho a ser percorrido pela mulher no papel que a sociedade patriarcal lhe reservou: a realização por meio do casamento. Tal realização geralmente ocorre por ser uma das primeiras decisões que a mulher toma: escolher com quem irá casar.

Diva relata que engravidar "antecipou os fatos": "Casei por eu quis, eu gostava dele, mas casei por que 
engravidei da minha filha, ai então antecipa os fatos. Mas eu gostava dele". Ela reforça que casou porque gostava do namorado. Nesse sentido, Pregnolato (2003) pontua a necessidade de buscar um parceiro, para com ele compartilhar os mais diversos momentos da vida, é uma característica tão típica do ser humano que o simples fato de se dar destaque a essa peculiaridade pode parecer, à primeira vista, redundante. Partir da ideia de homem como ser social por definição corresponde, na terminologia junguiana, a dizer que a busca do outro é arquetípica, que nesse contexto, refere-se a comportamento comum a toda a humanidade, desde todos os tempos.

Deve se lembrar que, na hora da escolha do parceiro ocorre uma busca para aquele que irá compartilhar momentos, e, nesses momentos, inclui-se a gravidez.

Antes de iniciar a discussão deste tema, é preciso rever o que Jung (2002) descreve sobre como ocorre à vontade própria de ter um filho e a mudança de condições: a mulher torna-se mãe, e o homem torna-se pai. Assim, ambos são privados da liberdade e tornam-se instrumentos da vida que prossegue. 0 relacionamento se conserva dentro dos limites da finalidade biológica do instinto: a conservação da espécie. Sendo que ao tornar-se pai/mãe, o indivíduo torna-se responsável por uma vida, e sai da condição de filho/a para ser pai/mãe.

A gravidez é um período no qual acontecem mudanças significativas na vida de uma mulher. Uma delas é deixar de ser filha para se tornar mãe, o que implica uma revivência da infância, na forma de lembranças e recordações. Assim, o desejo de ser mãe manifesta-se, por exemplo, nas brincadeiras de bonecas. Nessas, a menina tenderia a esboçar uma ideia de mãe (tal como a representa) e uma ideia de filha (tal como se representa como filha ou como representa um irmão como filho) (Stern, 1997).

Norma relata da experiência de ser mãe: "Depois ai em 1985, eu tinha 30 anos, nascimento da primeira filha. Foi aquela emoção de ser Mãe, de ser uma experiência nova, e com a primeira filha é uma grande expectativa, você não sabe como vai ser". Complementa que:

Em 1991, eu tinha 36 anos, nasceu meu segundo filho, o M. sempre foi um bebê mais carinhoso, eu cheguei da Inglaterra e logo depois já engravidei dele, foi naquela fase de voltar, mas ocorreu bem, eu já tinha uma experiência anterior. Sim, notei que a segunda foi mais fácil que a primeira, eu já tinha experiência, conhecimento, e eu já estava mais madura.
Diva ressalta que "Foram, a primeira não foi planejada, mas foi desejada, a segunda foi planejada e desejada. Eu aproveitei as duas gestações".

É possível observar, com o relato dessas mulheres, a presença do arquétipo materno. As falas transcritas anteriormente vão ao encontro do que Neumann (1995) descreve, que, quando ocorre o nascimento e com ele se conclui a transformação da mulher em mãe, põe-se em atividade uma nova constelação arquetípica, a qual remodela a vida da mulher até suas camadas mais profundas. Assim, o arquétipo materno é a matriz da autoconsciência feminina, estrutura a consciência da mulher num eixo próprio. Para tanto, faz-se necessário o sacrifício da filha, nutrida e protegida, para a iniciação da mãe que nutre e protege, vivenciando simbolicamente uma espécie de morte e renascimento. Quando ocorre que a mãe não se sentiu nutrida enquanto filha, ela pode querer ser suficientemente boa para o bebê para ser diferente da sua mãe, e dar o que não teve, ou isola-se fazendo o mesmo que sua mãe um dia fez para si. Nesse sentido, Galbach (1995) explica que "o nascimento de um primeiro filho representa "morrer" como jovem e "renascer como mãe", saindo da condição de quem precisa de cuidado, para o de dar cuidado.

É possível notar, no relato de Norma, que ela preferia que seus filhos brincassem na sua casa do que saíssem para brincar:

Eu sempre preferi que eles brincassem com os colegas em casa do que na rua, queria eles sempre ali, perto de mim, nos meus olhos, não gostava nem que ele fosse à casa de parente, viajasse, a menina até ia, mas era aquela dor, já o menino minha sogra queria levar ele, eu não deixava, e não queria, aí só se ele quisesse muito.

Foi possível compreender a partir dos relatos dessas mulheres e de consultas à literatura que as mães devem reconhecer esse outro lado da função materna para conseguirem se desvincular de seus filhos (ex: a criança precisa desmamar, ir à escola, etc). A separação será sempre angustiante para ambos os lados, mas necessária. Sozinha, a criança enfrenta inúmeras situações que a levarão a lidar com seus medos. Como fará isto, depende fundamentalmente da educação de seus pais. Se eles lhe ensinarem a se cuidar, ela aprende seus valores e se torna consequentemente, mais independente, não necessitando que outros façam por ela o que pode fazer por si mesma (Fedalto \& Araújo, 2001). 
Nota-se, na fala de Norma, o quanto foi difícil para ela deixar que os filhos crescessem, mesmo sabendo da necessidade. Era difícil ocorrer a separação, como é o caso da mãe na história Três Porquinhos, em que eles precisavam sair de casa para aprender a se proteger sozinhos. No pequeno trecho a seguir, pode-se fazer uma possível relação do relato de Norma com o que Pinto (2007, p. 184) pontua sobre o conto Três Porquinhos:

Nos Três Porquinhos ocorre a necessidade de fortalecimento do ego para enfrentar as adversidades do crescimento, deixando a casa da mãe para construir um mundo independente. Ao depararem com o Lobo Mau, o aspecto negativo da figura paterna, eles percebem que uma casa feita às pressas com material frágil é facilmente derrubada pelo sopro da violência. A experiência vai ensinar que somente uma casa solidamente construída (ego forte e em contato com a realidade) pode lhes oferecer um abrigo suficientemente seguro, no qual podem sobreviver longe da proteção materna.

A sociedade e a cultura supervalorizam o aspecto positivo da maternidade, não considerando a dimensão do feminino e, portanto, não orientando a mulher para essa iniciação. 0 tabu criado em torno da maternidade e as implicações da percepção de seu aspecto sombrio dificultam a verbalização da experiência, o que leva as mulheres a não revelarem umas às outras a situação conflitiva que se deparam ao nascimento de um filho, o que dificulta ainda mais a elaboração do processo. Portanto, os discursos de Diva e Norma sobre a dificuldade de deixar os filhos crescerem, mostra o lado pouco explorado, do sombrio e devorador da Grande Mãe.

Quando questionada sobre o que é ser uma boa mãe, Norma relatou que:

Eu acho que uma boa mãe num é assim, é..., eu acho que é cuidar bem deles, tanto na parte de dar carinho e atenção, como também alimentação, educação, e também num é assim eu quero isso e dou, eu quero aquilo e dou isso pra mim é errado, tem que ter um limite, lógico que eles tiveram tudo o que queriam e pedia, você tem condição você vai dando, mas num é muito correto não, eles choram $e$ você vai dando, eu acho que tem que ter limite.

Complementando e respondendo à mesma questão, Diva relatou que "Acho que tem que saber educar bem os filhos, com muito amor e paciência, e tem que saber educar né, por que senão...."
Também é possível fazer um paralelo das falas dessas mulheres e com o que Fedalto e Araújo (2001) apontam sobre o arquétipo de "mãe", que representa ambos os lados: o de protetora, que cuida e salva, e o de castradora, que limita e disciplina seus filhos, a fim de que se desenvolvam saudavelmente.

No que se refere ao arquétipo da Grande Mãe, a mãe assume a imagem inconsciente de nutridora dos afetos, dos sentimentos de confiança e estabilidade, estabelecendo a ligação entre o espiritual e o racional e, sobretudo, a relação que a filha terá com o mundo (Fedalto \& Araújo, 2001, p. 31).

Para Jung (2000), os traços essenciais do arquétipo materno são simplesmente a mágica autoridade do feminino; a sabedoria e a elevação espiritual além da razão; o bondoso, o que cuida, o que sustenta, o que proporciona as condições de crescimento, fertilidade e alimento.

0 mesmo conceito é explicado por Neumann (1995) que denota que o vínculo positivo com a Grande Mãe é também um pré-requisito psicológico para se tornar mãe, ter um bom relacionamento com o corpo e com o filho, sendo que se afastando da Grande Mãe leva a incapacidade de desenvolver qualidades maternais.

Quando perguntado sobre o que é ser mulher para Diva, ela relata que é: "a gente tem que se dividir, entre mãe, mulher, trabalhadora, dona de casa, em várias coisas, a vida da gente não é fácil [...]”. Tal trecho do discurso de Diva vai ao encontro do que Corso e Corso (2006) explicam: que até o começo da sociedade moderna, o amor materno não figurava entre os requisitos que uma mulher queria reivindicar para si. Nos primeiros momentos da emancipação feminina, era grande o desejo de desincumbir-se dos filhos e do lar. Atualmente o filho passa a ser um projeto prioritário para a mãe, mesmo antes de provar sua viabilidade (CORSO \& CORSO, 2006, p. 35).

Deve-se destacar, ainda, que a mãe dos tempos atuais associa sua vida à do filho, com seu trabalho, serviços de casa, vida pessoal, esposa, mãe, entre outras.

Para Norma, ser mãe é:

Eu acho que é a gente casar, aí os filhos aí são tudo né, depois deles você não imagina mais sua vida sem eles, é uma experiência e tanto, nossa pelo amor de Deus num dá pra se imaginar sem eles.

A partir desse recorte da fala de Norma, é possível fazer uma ligação com o conto $O$ Flautista 
de Hamelin, que relata a história de uma cidade (Hamelin, que foi infestada por ratos, quando um homem chega e com a flauta hipnotiza os ratos). De acordo com Corso e Corso (2006), esse conto descreve sobre as crianças, por não terem uma intuição de que podem ser o peso, e aos pais, para poderem pensar como seria enfrentar a casa vazia. Os mesmos autores complementam que os pais têm dificuldades de responder como seria a sua vida sem os filhos. Certamente seria mais fácil, mais barata, com mais tempo para eles, mas ficariam como a cidade de Hamelin, chorando pelas crianças que se foram, ou que não tiveram. Ter filhos não é um bem universal inquestionável, e cada vez mais, para sorte de todos, uma escolha.

\section{Considerações finais}

Os contos, desde sua origem, já exerciam função terapêutica, fato que se explica pela permanência e transmissão ao longo dos séculos. A linguagem dos símbolos permite conhecer os arquétipos, que são esquemas básicos da psique humana e se encontram no "inconsciente coletivo" - a camada profunda do inconsciente.

É importante ressaltar que os arquétipos são as realizações das tendências coletivas de agir de determinada forma, porém a forma como cada pessoa irá vivenciar esses arquétipos depende da singularidade de cada pessoa, depende da sua história de vida, atuando assim de forma positiva ou negativa.

Foi possível notar com a discussão do trabalho, que alguns contos de fadas e imagens arquetípicas femininas possuem relação ou influência direta no decorrer da vida dessas mulheres.

A importância em saber sobre essa relação favorece na compressão do feminino e assim, conhecer sobre suas idealizações do casamento e da maternidade leva a mulher em contato com seu processo de individuação.

Sobre o casamento, um aspecto importante apontado pelas mulheres desta amostra é que ambas as entrevistadas casaram-se com o primeiro namorado, e assim como nos contos de fadas, não há relato das personagens namorarem mais de um homem. Geralmente elas conhecem o príncipe, começam a namorar, casam e vivem felizes para sempre. Mas nem toda união é feita somente de momentos felizes. Outro ponto levantado é sobre a rotina, que gera conflitos e é normal haver discussões no casamento, sendo essas divergências importantes para o aparecimento da individuação. Saber como se dá a entrada na individuação é importante para o trabalho clínico, pois, nesse caso, a mulher amplia sua consciência a partir da integração de conteúdos inconscientes, aumenta sua capacidade de reflexão e autoconhecimento.

Conclui também a importância da gestação para essas mulheres, ao tornar-se mãe como instrumento da vida que prossegue. É um momento de renovação, para nascer mãe, é preciso morrer como filha. Ocorre uma mudança na identidade, e, neste caso, a individuação se dá pelo crescimento, em possibilitar que uma nova vida se desenvolva.

É salientar que a análise não termina aqui, pois há muito para ser estudado e revelado sobre discurso feminino.

\section{Referências}

Bettelheim, B. (1980). A psicanálise nos contos de fadas. Rio de Janeiro: Paz e Terra.

Corso, D. L., \& Corso, M. (2006). Fadas no divã. Porto Alegre: Artmed.

Di Yorio, V. (1996). Amor conjugal e terapia de casal: Uma abordagem arquetípica. São Paulo: Summus.

Estés, C. P. (1994). Mulheres que correm com os lobos. Rio de Janeiro: Rocco.

Fedalto, A. L. T., \& Araújo, A. C. de. (2001). Aspectos psicológicos do paciente diabético. Trabalho de Conclusão de Curso em Psicologia, Universidade Tuiuti do Paraná, Curitiba.

Galbach, M. R. (1995). Sonhos e gravidez: Iniciação à criatividade feminina. São Paulo: Paulus.

Giglio, Z. G. (1999). Contos maravilhosos: Expressão do desenvolvimento humano. Campinas: NEP; Ed. da Unicamp.

Guggenbhul-Craig, A. (1980). 0 casamento está morto, viva o casamento. São Paulo: Símbolo.

Jung, C. G. (1984). A natureza da psique. Petrópolis: Vozes. (Originalmente publicado em 1954). 
Jung, C. G. (2000). Os arquétipos e o inconsciente coletivo. Petrópolis: Vozes. (Originalmente publicado em 1976).

Jung, C. G. (2002). 0 desenvolvimento da personalidade. Petrópolis: Vozes. (Originalmente publicado em 1972).

Mendes, M. B. T. (2000). Em busca dos contos perdidos. O significado das funções femininas nos contos de Perrault. São Paulo: UNESP.

Neumann, E. (1995). História da origem da consciência. São Paulo: Cultrix.

PINTO, M. da C. (2007). Consciências em evolução. In A \& B Mudanças. 0 livro de ouro da psicanálise (pp. 183-209). Rio de Janeiro: Ediouro.

Pregnolato, M. (2003). Vida a dois: Um breve olhar sobre o relacionamento amoroso. Trabalho de Conclusão de Curso em Psicologia, Instituto Sedes Sapientiae, São Paulo, São Paulo.

Sanford, J. A. (1987). Os parceiros invisíveis: 0 masculino e o feminino dentro de cada um de nós. São Paulo: Paulus.

Sharp, D. (1993). Léxico Junguiano: Dicionário de termos e conceitos. São Paulo: Cultrix.
Stern, D. (1997). A constelação da maternidade. Porto Alegre: Artes Médicas.

Thompson, C. (1969). Evolução da psicanálise. Rio de Janeiro: J. Zahar.

Vargas, N. S. (1989). O casamento e a família como caminho de individuação junguiana. Junguiana - RSBPA, 7, 101-111.

Vargas, N. S. (2004). Terapia de casais: Uma visão Junguiana. São Paulo: Madras.

Varjão, C. V. S. G. (2009). A sombra nas relações de trabalho. Trabalho não publicado, Instituto Superior de Ciências da Saúde, Salvador.

Von Franz, M. L. (1990). A interpretação dos contos de fada. São Paulo: Paulinas.

Von Franz, M. L. (1995). A sombra e o mal nos contos de fadas. São Paulo: Paulinas.

Whitmont, E. C. (1969). A busca do símbolo: Conceitos básicos de psicologia analítica. São Paulo: Cultrix. 